\title{
Introduction to Middle Ear Implantable Hearing Devices
}

\author{
Hyung-Jong Kim \\ Department of Otorhinolaryngology-Head and Neck Surgery, Hallym University College of Medicine, Chuncheon, Korea
}

중이 이식형 보청기의 소개

김 형 종

한림대학교 의과대학 성심병원 이비인후과학교실

\begin{abstract}
The disadvantages of conventional hearing aids have prompted research by several investigators that ultimately led to the development of implantable hearing devices. This paper was aimed to review the history, indications, and surgical aspects of the implantable middle ear hearing devices. Available implantable hearing aids are partially implantable, or totally implantable, and have piezoelastic system or electromagnetic system. Their own peculiarities on candidacy and surgical procedure of the devices, including the Vibrant Soundbridge system, the Maxum system, the fourth-generation of Carina prosthesis, and the Esteem device, were reviewed. Implantable hearing aids, currently in the early stages of development, will be the major drivers of advancement in otologic practice in the 21 st century, improving the quality of life of an increasingly aged population, who requires hearing rehabilitation.
\end{abstract}

Key Words: Middle ear implantable device, Electromagnetic, Piezoelastic, Partially implantable, Totally implantable.

Received: January 1, 2016 / Accepted: March 10, 2016

Correspondence: Hyung-Jong Kim, Department of Otorhinolaryngology-Head and Neck Surgery, Hallym University Sacred Heart Hospital, Hallym University College of Medicine, 22 Gwanpyeong-ro 170beon-gil, Dongan-gu, Anyang 14068, Korea

Tel: +82-31-380-3841 / Fax: +82-31-386-3860 / E-mail: hjk1000@hallym.ac.kr

\section{INTRODUCTION}

기존에 사용되는 보청기는 외이도 폐쇄효과, 고주파수 난청 에서의 불충분한 이득, 음향 피드백(acoustic feedback) 등의 단점과 더불어 보기 흥하고, 장애가 있다는 것을 외부에 드러 낸다는 생각 때문에 임상에서 보청기 사용이 거부되거나 중단 되는 일이 흔하게 관찰된다. 보청기 사용자들의 이러한 불만 때 문에 세계적으로 이식형 보청기의 연구개발이 촉진되면서 이 단점들을 극복할 수 있도록 개발된 반이식형 또는 완전이식형 보청기들이 소개되었다(Bittencourt et al., 2014).

이식형 보청기에는 몇 가지 유형이 있다. 골전도 보청기 (bone anchored hearing aid, BAHA)는 귀 뒤의 두개골에 고정되어 뼈를 통해 소리를 전달하는 기기이고, Ret ro-X 유형은 귀 뒤 에 위치하여 외이도로 소리를 전달하는 기기이며, 중이 이식형 보청기(middle ear implantable hearing devices, MEIHD)는 소리를 고막을 통하지 않고 바로 이소골로 전달하는 기기이다.
(Figure 1) 그리고, 고심도 난청에서 내이로 직접 전기자극을 전 달하는 인공와우 혹은 와우이식(cochlear implant, $\mathrm{CI}$ )도 이식 형 보청기의 일종이라고 할 수 있다. 이식형 보청기는 완전이식 형(total implantable hearing aid)과 반이식형(partially implantable hearing aid)으로 나눌 수 있으며, 반이식형은 외부 에 송화기, 어음처리기와 전지가 있고 내부에 내부 수신코일 (internal receiving coil)을 포함하는 형태이고 완전이식형은 모두가 내부로 이식되는 것으로 크기가 커질 수 있고 복잡해질 수 있으나 미용적인 문제 등을 해결할 수 있어 향후에는 완전이 식형으로 개발방향이 이루어 질 것으로 예상된다(Lee, 2005). 본 논문에서는 최근 급격한 발전을 보이는 MEIHD에 관해 알 아보기 위하여 현재 임상에서 실제 시술되고 있는 대표적인 $\mathrm{MEIHD}$ 의 발전과정과 적응증, 그리고, 수술적 측면에 관해 문 헌고찰하고, 향후 전망을 알아보고자 하였다. 


\section{REVIEW}

MEIHD는 주로 중등도나 중등고도 이상의 난청을 대상으 로 1970년대에 제안된 이래 일본과 미국을 중심으로 활발히 연구가 진행되어 왔다. MEIHD는 송화기를 통해 들어온 소리 를 청력역치에 맞추어 증폭한 후 중이 내에 이식된 진동 트랜스 듀서(Vibration transducer)에 신호를 전달하여 소리와 같은 진 동신호를 발생시킴으로써 소리를 인식하도록 하는 장치이다. 소리전달의 외이도 경로가 없기 때문에 음향 피드백 현상이 없 고, 지나친 증폭을 사용하지 않아 소리왜곡도 작으며, 주파수

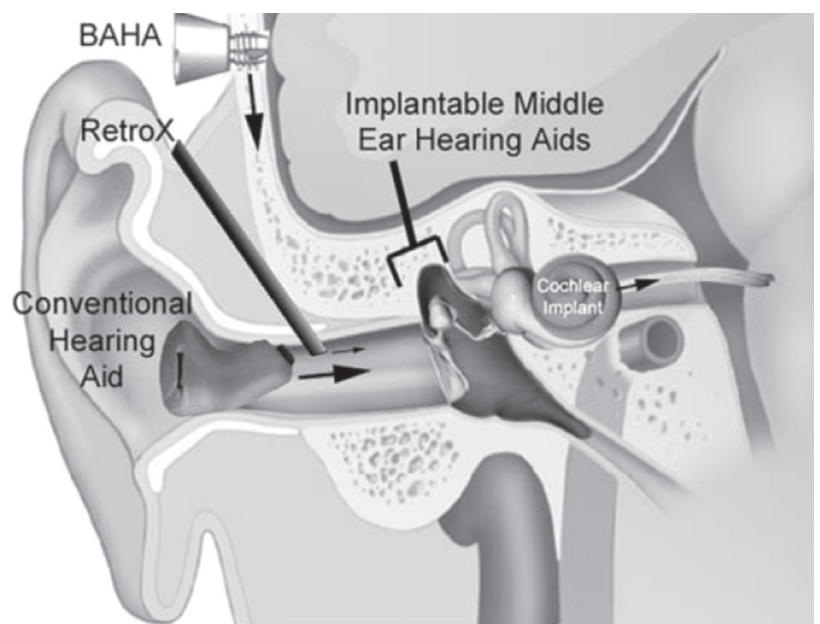

Figure 1. Various implantable hearing aids, BAHA, Retro-X, Middle ear implant, \& Cochlear implant.
특성이 우수한 원음을 비교적 그대로 내이에 전달하기 때문에 어음 명료도(speech intelligibility)가 기존 보청기에 비해 우수 하다. 중이에 이식되는 진동 트랜스듀서는 MEIHD에 있어서 가장 중요한 부분으로서 신호 전달 중 가장 마지막 부분에 위 치하고, 전달되는 소리를 효율적으로 진동신호로 변환시킬 수 있어야 한다. MEIHD는 진동 트랜스듀서의 구조에 따라 크게 압전 방식(piezoelectric type)과 전자 트랜스듀서 방식(electromagnetic type)으로 분류하는 방법을 주로 사용한다. 압전 방 식은 전기적인 성질과 기계적인 성질을 결합한 압전 변환 진동 자(piezoelectric crystal vibrator)를 직접 이소골에 연결하여 증폭하는 방식이고, 이것에는 등골 두부 위에 직접 연결시키는 Rion Implant와 Envoy가 있으며 침골 체부에 연결하는 Totally Implantable Communication Assistance (TICA)가 있다. 전자 트랜스듀서 방식은 형성된 전자기장이 이소골과 연결된 강자성체를 진동시키는 방식으로 이것은 이소골에 직접 연결되 지 않아도 되고 전자 트랜스듀서가 이소골 주위에 있으면 되는 방식이며 이것에는 침골에 연결하는 Vibrant Soundbridge (Med-El Corporation, Innsbruck, Austria), Carina (Otologics LLC, Boulder, Colorado, United States) 및 침등관절(incudostapedial joint)에 연결하는 Maxum(Ototronix LLC, Houston, Texas, United States) 방식이 있다. MEIHD를 정리하여 Table 1 에 나타내었다.

Table 1. Comparison of middle ear implantable hearing aid

\begin{tabular}{|c|c|c|c|c|c|c|c|c|}
\hline Device & Manufacturer & Sensor & Actuator & $\begin{array}{l}\text { Regulatory } \\
\text { approval }\end{array}$ & Implanted & $\begin{array}{c}\text { Surgical } \\
\text { placement }\end{array}$ & MRI & $\begin{array}{c}\text { Special advantage/ } \\
\text { Disadvantage }\end{array}$ \\
\hline TICA & Implex AG & $\begin{array}{l}\text { Piezoelectric, } \\
\text { subcutaneous } \\
\text { in EAC }\end{array}$ & $\begin{array}{l}\text { Piezoelectric, } \\
\text { to incus }\end{array}$ & $\begin{array}{l}\text { Europe CE } \\
\text { Mark, } 1998\end{array}$ & Total & $\begin{array}{l}\text { Transmastoid } \\
\text { malleus } \\
\text { transection }\end{array}$ & + & \\
\hline Esteem & $\begin{array}{l}\text { Envoy } \\
\text { medical, } \\
\text { Intl. }\end{array}$ & $\begin{array}{l}\text { Piezoelectric, } \\
\text { coupled to } \\
\text { malleus/TM }\end{array}$ & $\begin{array}{l}\text { Piezoelectric, } \\
\text { to stapes }\end{array}$ & 2011 FDA & Total & $\begin{array}{l}\text { Transmastoid } \\
\text { incus removal }\end{array}$ & + & $\begin{array}{l}\text { Very high power; } \\
\text { requires incus } \\
\text { removal }\end{array}$ \\
\hline Carina & Otologics LLC & $\begin{array}{l}\text { Electric, } \\
\text { coupled to } \\
\text { micorphone }\end{array}$ & $\begin{array}{l}\text { Electric } \\
\text { coupled to } \\
\text { incus }\end{array}$ & $\begin{array}{l}\text { Europe CE } \\
\text { Mark, U.S. FDA } \\
\text { Clinical trials: } \\
\text { phase II }\end{array}$ & Total & Transmastoid & $\begin{array}{l}\text { Not } \\
\text { compatible }\end{array}$ & \\
\hline $\begin{array}{l}\text { Vibrant } \\
\text { sound- } \\
\text { bridge }\end{array}$ & MED-EL & $\begin{array}{l}\text { External } \\
\text { BTE microphone }\end{array}$ & $\begin{array}{l}\text { Magnetic, } \\
\text { clipped to } \\
\text { incus }\end{array}$ & $\begin{array}{l}\text { Approved. } \\
\text { U.S. FDA } \\
\text { Europe CE Mark }\end{array}$ & Partial & $\begin{array}{l}\text { Transmastoid } \\
\text { and endaural }\end{array}$ & $1.5 \mathrm{~T}$ & $\begin{array}{l}\text { First U.S. } \\
\text { FDA approved, } \\
\text { largest } \\
\text { install base }\end{array}$ \\
\hline Maxum & Ototronix LLC & $\begin{array}{l}\text { External ITC } \\
\text { or BTE }\end{array}$ & $\begin{array}{l}\text { Magnetic, to } \\
\text { incus }\end{array}$ & U.S. FDA 2001 & Partial & $\begin{array}{l}\text { Endaural, } \\
\text { clip on ossicle }\end{array}$ & - & \\
\hline
\end{tabular}




\section{압전 세라믹 방식}

Esteem system(Envoy Medical Corporation, Minnesota, United States)

Rion 방식은 일본 Yanagihara et al.(1984)에 의해 개발된 반 이식형 보청기로 침골과 추골, 고막을 제거한 후에 압전 방식의 진동자를 등골 두부에 직접 연결하고 연골에 의해 중이의 새로 운 외측벽을 형성하고, 어음처리기와 송화기는 BTE형으로 기 존의 보청기와 비슷한 형태를 취하며 $500 \mathrm{~Hz}, 1 \mathrm{KHz}, 2 \mathrm{KHz}$ 의 청력이 $50 \mathrm{~dB}$ 을 넘지 않는 혼합성 난청환자와 기존의 중이 수술로 교정할 수 없는 이소골의 손상이 있는 환자를 대상으 로 임상연구를 진행하였다. Esteem은 Rion 방식을 이어 받아 압전 기술을 바탕으로 15 년간의 임상연구 후에 송화기를 쓰지 않고, 소리를 직접 고막과 이소골을 통해 수신하는 방식이며 압 전 소자에 침모양의 팁을 설치하여 등골에 접촉시킴으로써 신 호를 전달하도록 되어 있으며 특히 추골에도 압전 소자를 설치 하여 마이크로 이용하도록 고안되었다(Kraus et al., 2011). 완전 이식형 보청기이며 인공 심박조율기에 사용되는 기술을 사용하 여 배터리를 7 10년에 한번씩 교체해 주면 되고, 2011년 미국 $\mathrm{FDA}$ 승인을 받았다. 외이도 공명을 이용할 수 있어 원래의 소 리에 좀 더 가까운 신호를 전달할 수 있고 완전 이식형이므로 미용적 장점이 있으나 주기적으로 배터리를 교체하여야 하고 이소골을 통한 음향 피드백이 발생할 수 있으며 이소골의 동작 에 이상을 주지 않도록 매우 정밀하게 장치를 이식해야 하므로 수술이 힘든 단점이 있다. 적용대상은 18세 이상으로 $500 \mathrm{~Hz}$ 에 서 $4 \mathrm{KHz}$ 까지 $35 \mathrm{~dB}$ 에서 $85 \mathrm{~dB}$ 의 환자를 대상으로 하며 반대 측보다 같거나 나쁜 청력을 가져야 하며 어음 분별력이 $60 \%$ 는 넘어야 한다.

\section{TICA(Implex AG, Munich, Germany)}

TICA는 1990년대 초 독일의 Leysieffer와 Zenner에 의해 처 음 고안되었으며(Zenner \& Leysieffer, 2001; Zenner \& Jorge, 2010)이후 Implex AG 사에서 생산한 모델로 1998년부터 유럽 에서 사용되었으며 현재 임상에서 더 이상 사용되지 않으나 완 전이식형 보청기의 연구개발에 초기 공헌을 하였다. 작동장치 (actuator)는 $0.5 \mathrm{~mm}$ 티타늄 탐침이 침골에 연결된 상태로 작 동하여 전력소모를 최소화 하였으며 2 시간 충전으로 50 시간 을 사용할 수 있다. 직경 $4.5 \mathrm{~mm}$ 의 송화기가 고막 가까운 외이 도의 피하에 이식됨으로 이개와 외이도의 증폭효과를 얻을 수 있고 소리의 방향성이 좋은 장점을 가지고 있다. 다른 이식형 보청기와는 다르게 높은 주파수에서 큰 증폭을 얻을 수 있게 고안되었고 티타늄 소재를 사용하여 MRI 촬영도 가능하지만 음향 피드백 현상이 발생할 수 있는 것으로 보고되고 있다. 적
용은 $2 \mathrm{KHz}$ 이하에서는 $30 \mathrm{~dB}$ 이하의 청력을 가지고 $3 \mathrm{KHz}$ 이 상에서는 $90 \mathrm{~dB}$ 까지의 중등도 고도난청환자를 대상으로 한다.

\section{전자 트랜스듀서 방식}

\section{Carina}

Middle ear tranducer(MET) 방식은 미국 Washington 대학 의 J. M. Fredrickson와 Otologics LLC(Boulder, Colorado, USA)에 의해 개발된 것으로 영구자석과 코일을 이용하여 진동 을 발생시키고 트랜스듀서 팁을 침골에 고정함으로써 소리 신호 를 전달시키도록 반이식형 보청기이다(Otologics LLC, 2011). 이 방식은 수술시 트랜스듀서 및 지지체의 고정이 힘들고 이소 골을 훼손시키지 않아야 하는 어려움이 있으며 현재 연구가 사 실상 중단된 상태이다. Carina 방식은 MET를 계승한 Otologics사의 완전이식형 보청기이며 4세대까지 개발되었고, 유럽에서 $\mathrm{CE}$ 마크를 획득하고, 미국 $\mathrm{FDA}$ 에 임상실험을 위한 phase II 임 상시험 중에 있다.

Carina 방식은 1) 이식기기, 2) 이식프로그램장비, 3) 리모컨, 4) 충전지의 네 요소로 되어있고(Otologic LLC, 2011), 수술의 적응대상은 (1) 14 세 이상, (2) 후천성 감각신경성난청, (3) 500 $\mathrm{Hz}, 1 \mathrm{kHz}, 2 \mathrm{kHz}$ 순음역치평균이 $40 \sim 80 \mathrm{~dB}$, (5) air bone gap $10 \mathrm{~dB}$ 이내, (6) 단어인지도 40\% 이상, (7) 진행성 또는 변동 성 난청은 제외, (8) realistic expectation일 것 을 포함한다.

\section{Vibrant soundbridge}

Vibrant Soundbridge(VSB)는 미국 Stanford의 Goode(1995) 가 수행한 연구를 기반으로 Symphonix Device A사(San Jose, CA, USA)에 의해 개발된 이후 1998년 유럽에서 처음 승인되었 고 2000년에 반이식형 보청기로서는 최초로 미국 $\mathrm{FDA}$ 의 사용 승인을 획득하였으며 임상에 적용된 이후 유럽과 세계적으로 1000건 이상 시술되었다.(Colletti et al., 2006; Colletti et al., 2009; Colletti et al., 2011) VSB는 floating mass transducer (FMT) 라는 새로운 트랜스듀서를 사용하는 방식으로 기존의 전자 트랜스듀서와는 달리 코일 내부에 영구자석을 위치시킴 으로써 진동효율을 극대화 하였고 작은 클립을 이용해서 침골 아랫부분에 고정하고, 등골 아랫부분에 위치시킴으로써 효율적 인 진동전달이 이루어지도록 고안되었다(Cremers et al., 2010; Sterkers et al., 2003). 이 방식은 진동과 주파수 특성이 우수하 고 진동효율이 높으며 수술이 비교적 간단하여 다른 $\mathrm{MEIHD}$ 에 비교하여 상품성이 높은 것으로 평가되고 있다. Symphonix Device A사는 2003년에 보청기 및 인공와우 제작사인 MED$\mathrm{EL}$ 사에 인수되었고, 어음처리기가 수 차례 업데이트 된 후 현 재는 Amade 외부장치가 개발된 상태이다. VSB는 수술적으로 
삽입하는 vibrating ossicular prosthesis (VORP) 내부장치와 자석을 사용해 두피에 부착하는 어음처리기 외부장치로 구성 되어 있다. 적용대상은 (1) 18 세 이상, (2) 기존 보청기 사용의 금 기증, 또는 기존 보청기로 이득이 없는 경우, (3) 외이 또는 중이 기형, (4) 2년 이상 호전 없는 난청(감각신경성, 전음성 및 혼합성 난청), (5) 만성중이염 후유증으로 개방형공동이나 이소골이 없 는 경우, 또는 이경화증에서 등골수술 금기증을 포함한다.

\section{Maxum}

Soundtec사(Oklahoma city, OK, USA)의 Direct drive hearing system(DDHS)는 1980년대 초 Hough의 연구(Hough et al., 2002)를 기초로 전자 트랜스듀서 방식으로 반이식형으로 개발 되었고, 현재 미국 2001년 FDA의 승인을 받았다. 이소골과 연 결되는 부분과 외이도에 위치되는 전자기장 코일과 $\mathrm{BTE}$ 언어 처리기의 세 부분으로 나누어지며 이식되는 부분은 티타늄으 로 싸여있으며 침등관절에 부착된다. Maxum 방식은 Soundtec 사의 DDHS의 기술을 토대로 하여 Ototronix LLC(Houston, $\mathrm{TX}, \mathrm{USA}$ )에서 개발한 전자 트랜스듀서 방식으로 반이식형 보 청기이다(Pelosi, et al, 2014). Maxum 방식은 외부장치 어음처 리기와 마그넷과 케이스와 거기에 연결된 티타늄 고리으로 구 성된 내부장치로 되어 있으며 수술을 통해 티타늄 고리를 침등 골 관절에 부착하여 마그넷이 고막과 와우 갑각부(promontory) 사이에 닿지 않도록 위치시켜야 한다. 수술의 적응대상은 (1) 18 세 이상, (2) 중등도 내지 중등고도 감각신경성난청이고, 전음성난청, 후미로성 또는 중추성난청과 중이감염, 고막천공, 심한 이명은 수술을 권유하지 않는다.

\section{향후 전망}

전세계에서 연구되고 있는 MEIHD는 위에서 열거한 바와 같이 여러 유형으로 나뉠 수 있고, 각자 특성에 따라 장점과 단 점을 가진다. 현재까지의 개발현황을 보면 압전 방식이든 전자 트랜스듀서 방식이든 원하는 진동력을 발생시킬 수만 있다면 상용화가 가능할 것으로 보인다. 그러나 음누가현상(loudness recruitment effect)등 심한 감각신경성난청에서 발생하는 특성 에 맞도록 정밀하게 조절되지 않으면 진동신호가 오히려 또 다 른 소음성 난청의 원인이 될 수도 있으므로 주의해야 한다. 위 의 MEIHD중 완전이식형 Esteem 방식은 송화기가 외부에 드 러나지 않는 점과 미용적인 면에서 상당히 매력적이고, 임상 결 과도 만족스럽게 보고되고 있다. 수술과정이 복잡하고, 트랜스 듀서 크기가 큰 것과 침골 일부를 제거해야 하는 점이 문제점 들이 해결되면 좀더 상용화에 가속도가 붙을 것으로 기대된다. 한편, 현재 세계적으로 $\mathrm{MEIHD}$ 와 $\mathrm{CI}$ 의 기술을 통합하려는 움
직임이 있다. 이는 신호처리기를 하이브리드 타입으로 제작하 고 환자에게 시술할 때 $\mathrm{CI}$ 에 필요한 전극과 $\mathrm{MEIHD}$ 에 필요한 진동 트랜스듀서를 함께 이식한 후 필요에 따라 기기를 선택할 수 있도록 하는 아이디어이다. 이는 앞으로 이식형 보청기의 표 준이 될 것으로 기대되지만 현재 상용화 되어있는 $\mathrm{CI}$ 시장 중 대부분을 독점하고 있는 호주 Cochlear사의 정책에 따라 그 방 향이 정해질 것으로 판단되고 그런 이유에서 현재는 하이브리 드 방식의 통합 시스템보다는 각 시스템의 개발 및 성능 개선에 연구의 초점이 맞추어져 있다.

고령의 인구가 점차 증가되고 있는 전세계적 현황과 전자기 술의 눈부신 발전과 삶의 질을 높이려는 욕구가 맞물리며 난청 재활 시장은 더욱 확대될 것으로 예상된다. 대부분의 전문가들 은 CI보다는 MEIHD의 시장성이 더욱 크다고 예상하고 있다. MEIHD 상품화를 위해서는 아직 해결해야만 하는 난제들이 많이 남아 있어 실제로 상용 보급되는 시점은 아직 예측하기 어렵지만, 이미 시작된 것으로 생각되고, 앞으로 얼마나 적극적 으로 연구인력과 재정의 투자가 이루어지는지가 관건이라고 생 각된다.

중심 단어 : 중이이식형 보청기·전자기장·압탄성·부분이식형· 완전이식형.

\section{REFERENCES}

Bittencourt, A. G., Burke, P. R., Jardim, I. S., Brito, R., Tsuji, R. K., Fonseca, A. C., et al. (2014). Implantable and semi-implantable hearing AIDS: a review of history, indications, and surgery. International Archives of Otorhinlaryngology, 18(3), 303-310.

Colletti, V., Soli, S. D., Carner, M., \& Colletti, L. (2006). Treatment of mixed hearing losses via implantation of a vibratory transducer on the round window. International Journal of Audiology, 45(10), 600-608.

Colletti, V., Carner, M., \& Colletti, L. (2009). TORP vs round window implant for hearing restoration of patients with extensive ossicular chain defect. Acta Oto-Laryngologica, 129(4), 449-452.

Colletti, L., Carner, M., Mandala, M., Veronese, S., \& Colletti, V. (2011). The floating mass transducer for external auditory canal and middle ear malformations. Otoloty and Neurotology, 32(1), 108-115.

Cremers, C. W. R. J., O’Connor. A. F., Helms. J., Roberson, J., Claros, P., Frenzel, H., et al. (2010). International consensus on Vibrant Soundbridge ${ }^{\circledR}$ implantation in children and adolescents. International Journal of Pediatric Otorhinolarygology, 74(11), 1267-1269.

Goode, R. L., Rosenbaum, M. L., \& Maniglia, A. J. (1995). The history and development of the implantable hearing aid. Otolaryngologic Clinics of North America, 28(1), 1-16.

Hough, J. V., Matthews, P., Wood, M. W., \& Dyer, R. K. J. (2002). Middle ear electromagnetic semi-implantable hearing device: results of the phase II SOUNDTEC direct system clinical trial. Otoloty and Neurotology, 23(6), 895-903.

Kraus, E. M., Shohet, J. A., \& Catalano, P. J. (2011). Envoy esteem totally implantable hearing system: phase 2 trial, 1-year hearing results. Otolaryngology-Head and Neck Surgery, 145(1), 100-109.

Lee, S. H. (2005). Implantable hearing aids. Korean Journal of Audiology, 9(2), 113-124

Otologics LLC. (2011). Rev. B Surgical Training Manual European Union 
(D109629). Fully-implantable ossicular dtimulator MET. Boulder, CO: Otologics LLC.

Pelosi, S., Carlson, M. L., \& Glasscock, M. E. (2014). Implantable hearing devices: the Ototronix MAXUM system. Otolaryngologic Clinics of North America, 47(6), 953-965.

Sterkers, O., Boucarra, D., Labassi, S., Bebear, J. P., Dubreuil, C., Frachet, B., et al. (2003). A middle ear implant, the Symphonix Vibrant Soundbridge: retrospective study of the first 125 patients implanted in France. Otoloty and Neurotology, 24(3), 427-436.

Yanagihara, N., Suzuki, J., Gyo, K., Syono, H., \& Ikeda, H. (1984). Develop- ment of an implantable hearing aid using a piezoelectric vibrator of bimorph design: state of the art. Otolaryngology-Head and Neck Surgery, 92(6), 706-12

Zenner, H. P., \& Leysieffer, H. (2001). Total implantation of the Implex TICA hearing amplifier implant for high frequency sensorineural hearing loss: the Tubingen University experience. Otolaryngologic Clinics of North America, 34, 417-446.

Zenner, H. P., \& Rodriguez, J. J. (2010). Totally implantable active middle ear implants: ten years' experience at the University of Tübingen. Advances in Oto-Rhino-Laryngology, 69, 72-84. 